\title{
Pilot study of a dedicated education unit: Lessons learned
}

\author{
Karen J. Polvado ${ }^{* 1}$, Susan Sportsman ${ }^{2}$, Pam Bradshaw ${ }^{3}$ \\ ${ }^{1}$ Midwestern State University, Wichita Falls, TX, United States \\ ${ }^{2}$ Academic Consulting Group, Elsevier Education, Maryland Heights, MO, United States \\ ${ }^{3}$ Shannon Medical Center, San Angelo, TX, United States
}

Received: July 23, 2015

DOI: $10.5430 /$ jnep.v5n12p122
Accepted: September 6, $2015 \quad$ Online Published: September 28, 2015

URL: http://dx.doi.org/10.5430/jnep.v5n12p122

\begin{abstract}
Background and objective: Nursing programs in Australia, New Zealand, and the United States are implementing Dedicated Education Units (DEU) as an innovative approach to provide clinical experiences for undergraduate nursing students. In August 2014 a university in Texas received a state grant to institute a pilot implementation of a DEU as a means of increasing the number of pre-licensure nursing students in the BSN program. The following objectives were designed to provide structure to implement and evaluate the DEU project: (1) Develop and implement a DEU model for pre-licensure nursing clinical education in four medical-surgical courses, using two nursing units at a local regional hospital; (2) Test the effectiveness of the DEU model of clinical education for pre-licensure nursing students; and (3) Increase the number of BSN-prepared nurses serving as DEU Clinical Instructors who enroll in a MSN-Nurse Educator program by six in the first semester of the grant.

Methods: A variety of methods were used to evaluate effectiveness of this project, including focus groups of participants; qualitative assessment of the project orientation process for students, faculty and staff; quantitative analysis of examination scores, course scores, competency evaluations, and enrollment data.

Results: Project evaluation revealed some positive results; however, problems related to orientation and ongoing support were seen as a barrier to successful implementation. Work overload for the Clinical Instructors also negatively impacted the effectiveness of the project. The number of students involved in this project was dictated by the space available in the designated DEUs. Even though the small sample size was insufficient for a research study, the results of this project may be of interest to others implementing a DEU.

Conclusions: This paper focuses on lessons learned from the implementation a DEU pilot project and provides a number of suggestions for addressing challenges. The analysis of the results of this pilot project and related recommendations to avoid or ameliorate the challenges may be instructive for other schools planning to initiate a DEU.
\end{abstract}

Key Words: Dedicated education unit, Innovation in clinical learning, Program evaluation, Clinical instructors, Nursing education

\section{INTRODUCTION}

Innovation carries with it the risk of failure. No matter how exciting a new idea may be, there is the potential that implementation will not result in the desired outcomes. A pilot study can often test the innovation, providing information to improve the project over time. This article describes the twoyear initial implementation of a Dedicated Education Unit (DEU) in a Texas pre-licensure BSN program and focuses on the "lessons learned" from this innovative approach to clinical teaching. This analysis and related recommendations

*Correspondence: Karen J. Polvado; Email: karen.polvado@mwsu.edu; Address: Midwestern State University, Wichita Falls, TX, United States. 
to avoid or ameliorate the challenges may be instructive for other schools planning to initiate a DEU.

\subsection{Dedicated education units}

Dedicated Education Units (DEUs), as a model of clinical instruction for nursing students, was initially developed in Australia at Flinders University School of Nursing and Midwifery in 1999. Nursing faculty in Australia who implemented the first DEU surmised that clinical instruction is much like a swamp. It is "a rich environment, which initially may seem wet, messy, boggy, opaque, threatening, but which in reality provides the nutrients, networks, and constant ebb and flow of new experiences and relationships that novice nurses need to mature."[1]

The Australian DEU developers set out to find strategies to help nursing students to more effectively make the transition from "struggling through a swamp" to effective novice practitioner. The DEU model uses specially prepared clinical nurses on a designated nursing unit who play a major role in students' clinical instruction and thus, their transition as a practicing nurse. This innovative model is designed to foster a more positive clinical learning environment, maximize student learning outcomes, and nurture a closer partnership between clinicians and academics. Recognition of mutuality, respect and trust among all stakeholders is central to its success. ${ }^{[2]}$

The DEU model was first implemented in the United States in 2003 at the University of Portland School of Nursing. Similar to the approach in Australia, this model was designed to leverage the use of staff nurses in clinical education, building upon the belief that clinical nurses are vital to development of students' professional skill and knowledge. ${ }^{[3]}$ Staff nurses are selected to be Clinical Instructors (CI) to provide direct supervision for individual students. Some basic assumptions for CIs working on a DEU are as follows:

- CIs serve as the primary clinical instructor for individual students, entering into an ongoing mentoring relationship with the student.

- Nurses who choose to be a CI are committed to teaching, recognizing that it improves their practice and satisfaction with their job.

- The partnership between faculty and CI is critical for success of the DEU. ${ }^{[4]}$

The role of the faculty working with DEUs is to coach CIs in their new teaching role, maintain collaborative relationships with unit staff members, and promote student learning. ${ }^{[5]}$ The learning environment on these units is designed to provide a positive clinical learning environment for students on

Published by Sciedu Press an ongoing basis by capitalizing on the expertise of both clinicians and faculty. ${ }^{[6]}$

A primary advantage of using the DEU model for prelicensure clinical education is the consistency of location and preceptors throughout much of the students' educational experience. In traditional clinical experience, students are assigned to multiple units throughout their course of study. Students complain that "as soon as we have been on the unit long enough to get the hang of things, we rotate to a new hospital or unit."[7] Use of the DEU model for a significant portion of required clinical experiences answers this complaint.

Significant differences in learning experiences of students in units that were part of a DEU model compared to students receiving traditional clinical experiences are an example of the positive effect of remaining on one nursing unit for a significant portion of clinical rotations. ${ }^{[8]}$ Students were more likely to report that unit nurses helped them develop clinical skills and they felt more in charge of their own learning experiences when they were assigned to a DEU. These findings were validated when researchers found that students assigned to a DEU were more likely to agree that their clinical learning experience was high quality and they had a consistent learning environment than students in a traditional experience. ${ }^{[5]}$

The on-going relationships forged among staff and students within the DEU results in a "community of practice" that supports student learning. A community of practice is a group of people who engage in the process of collective learning regarding a specific area of practice. In pursuing their interest, members engage in joint activities and discussions, help each other, and share information. They build relationships that enable them to learn from each other to improve the practice. Such social participation enhances learning, which may improve student and staff satisfaction. ${ }^{[9]}$ This level of social participation supports student engagement in their own learning, a critical component for successful outcomes. ${ }^{[10]}$

The effectiveness of a DEU model in developing a "community of practice" was confirmed in 2009. [11] Interviews with 34 DEU participants found that one reason for success of the DEU was key relationships within the DEU. The specific themes threaded through the interviews included (a) engaging in recurring communication to achieve shared objectives, (b) problem solving to maintain valued relationships, (c) working together toward mutual outcomes, (d) recognizing unfamiliarity in changing roles and responsibilities, (e) valuing interdependence, complementary competence, and equalizing power balance, (f) witnessing the effect of teamwork upon positive change and quality improvement, and 
(g) advocating for a DEU future amidst low certainty and little agreement on next steps. ${ }^{[11]}$ The effect of a "community of practice" appears to reduce the gap between classroom and clinical teaching, making better use of resources and partnerships available in the community. ${ }^{[12]}$

The use of a DEU also addresses the shortage of nursing faculty in many locales. In 2014, the American Association of Colleges of Nursing (AACN) reported a national vacancy rate of 8.3 percent. ${ }^{[13]}$ The aging of nursing faculty exacerbates this problem. In 2008, one report suggested that half of U.S. nursing school faculty plan to retire within ten years. ${ }^{[3]}$ With the current improvement in the U.S. economy, this prediction is likely to be correct. Innovative strategies to combat this ongoing shortage of faculty must be put in place to support preparation of the required number of nurses in the U.S. in the future. The initial evaluation of the impact of the DEU model at the University of Portland found large savings in clinical faculty and the sites needed to educate students. In 2002, prior to implementation of the model, 227 undergraduate students at the University of Portland had clinical experience on 14 medical-surgical units. Following implementation, 333 students completed their medical-surgical experience in 6 specific nursing units. The researchers suggested that 25 medical-surgical units and 14 to 15 clinical faculty members would have been required in a traditional model to offer the education provided by the DEUs. ${ }^{[3]} \mathrm{Sim}-$ ilarly, according to a video from Champion Nursing, two years after a DEU model was implemented at Massachusetts General Hospital, an increased number of students had been admitted to partnering schools of nursing. ${ }^{[14]}$

\subsection{Purpose}

In August 2010, a School of Nursing (SON) in Texas was awarded a grant by the Texas Higher Education Coordinating Board (THECB) to fund a project entitled "Use of a Dedicated Education Unit to Increase Student Enrollment." The purpose of the grant competition was to develop innovative strategies to increase the number of registered nurses to address the ongoing Texas shortage. The goal of this specific project was to increase the number of pre-licensure nursing students admitted to the SON pre-licensure BSN program by 55 students over the two year grant period.

\subsection{Objectives}

The following objectives were designed to provide structure to meet the goal of the project.

(1) Develop and implement a DEU model for prelicensure nursing clinical education in four medicalsurgical courses, using two nursing units at a local regional hospital;
(2) Test the effectiveness of the DEU model of clinical education for pre-licensure nursing students;

(3) Increase the number of BSN-prepared nurses serving as DEU Clinical Instructors who enroll in the SON MSN-Nurse Educator program by six in the first semester of the grant.

The project was developed by the Chair of the School of Nursing, the Dean of the College of Health Sciences and Human Services, and the Chief Nursing Officer/Vice President of Clinical Services of a 300-bed community hospital supplying units dedicated to nursing students. Therefore, this project had strong administrative support from both organizations involved in the project.

\section{METHODS}

\subsection{Objective 1: Develop and implement a DEU}

The development and implementation of the DEU model was the major component of the grant's first year activities. In this project, six BSN-prepared RN hospital employees were selected as CIs to supervise student clinical experiences in the two designated units. The role of these BSN-prepared nurses was to supervise students in a precepted clinical model, working one-on-one with a student on an ongoing basis, under the direction of a SON faculty member who was not continuously on site. The rules and regulations of the Texas Board of Nursing regarding the preceptor model allow one faculty member to supervise and direct the clinical experiences for up to 24 students, compared to a traditional model, which requires one faculty member in a clinical setting for no more than ten students.

\subsubsection{Selection of clinical instructors}

In order to insure that the CIs responsible for supervising student clinical experiences were competent practitioners and enthusiastic about their teaching role in the DEU, the nursing leaders at the university and hospital developed an application process for the CIs. The hospital Chief Nursing Officer/Vice President of Clinical Service sent a letter introducing the opportunity to be a CI to all BSN-prepared employees with at least one year of experience. Although the CIs did not receive additional pay for serving in this role because of the rules of the grant, this experience was designed to be a criterion of the hospital's clinical ladder used in pay raise decisions and promotions.

\subsubsection{Support roles in the DEU}

The SON DEU project allocated two MSN-prepared nurses to assist in the implementation of the DEU. One was a SON faculty member who provided coordination with other faculty assigned to the four medical-surgical courses involved 
in the project and served as the clinical faculty for the students in each medical-surgical course assigned to the DEU. The second support person was a nurse educator employed by the hospital. Her role was to serve as an ambassador for the project with the hospital staff. Both of these nurses were involved in the development of the project and in the orientation of the staff.

\subsubsection{Staff orientation}

To prepare for implementation of the project, 10 hospital directors, managers, and administrators of the hospital, as well as faculty involved in the project participated in an orientation prior to assignment of the initial cohort of students to the DEU. The orientation included an overview of project objectives and underlying theoretical framework, including Wenger's "community of practice" and its applicability to clinical practice; a presentation on the principle of clinical teaching; and a review of the clinical objectives of SON students at various levels in the program. ${ }^{[9]}$ The goals, objectives and methodology of the grant and the roles of all parties involved in the implementation of the DEU were also reviewed.
Following the initial orientation and agreement on the process, staff nurses on the selected DEU units were educated about and invited to participate in the project. In addition, once the CIs were chosen, they were oriented on the process and expectations of the DEU program. Each CI had a faculty member as a partner.

\subsubsection{Selection of students}

To increase the number of number of students enrolled in the SON by 55 , approximately 15 qualified students per semester had to be admitted above the 80-90 students typically enrolled. For each of the four cohorts admitted, 10 students were randomly selected to be included in the DEU group and 20, in the control group. A maximum of 10 students was selected per cohort because of the limited clinical space available in the designated DEUs. In order to participate in either the DEU or the control group, students had to agree to complete a demographic data sheet, the Student Survey of Engagement (SSE) instrument, and the pre- and post-test of the QSEN Evaluation. They also gave permission for their course grades and other measures of competency to be included in the project evaluation. Table 1 provides an overview of the participation of students in the project.

Table 1. Student participation in the DEU

\begin{tabular}{llll}
\hline Cohort number & Total number of students admitted & Number of students in the DEU & Number of students in control group \\
\hline 1 & 107 & 8 & 15 \\
2 & 93 & 12 & 21 \\
3 & 78 & 10 & 17 \\
4 & 95 & 10 & 16 \\
Total & $\mathbf{3 7 3}$ & $\mathbf{4 0}$ & $\mathbf{6 9}$ \\
\hline
\end{tabular}

In the first cohort, 2 students assigned to the DEU and 6 students assigned to the control group refused to participate in the project. As a result, in the second cohort, the number of students assigned to the DEU was increased to 12 and the number assigned to the control group was 24 . In this cohort, all those selected for the DEU participated and three members of the control group elected not to participate. In cohorts 3 and 4, several of the control group also declined to participate ( 3 in cohort 3 , and 4 in cohort 4 ).

\subsubsection{Student orientation}

During the first clinical orientation day each semester, all students enrolled in the first medical-surgical course were given an overview of the DEU project. The students randomly selected for the DEU and control groups were given an additional, more in-depth explanation of the project prior to completing the required consent forms for participation.

\subsection{Objective 2: Test the effectiveness of the DEU}

The effectiveness of the DEU model in this project was tested using multiple quantitative measures, which are outlined in Table 2. Hypotheses were developed to direct the evaluation of this project.

\subsection{Objective 3: Increase the number of CIs enrolled in the nurse educator program}

There were few MSN-prepared nurses in the community in which this project was implemented. As a strategy to encourage local nurses to obtain a MSN and develop expertise in nursing education, the project provided funding for the six BSN-prepared nurses selected for the CI positions to enroll in the SON MSN-Nurse Educator Program in fall 2010. To provide an additional incentive for nurses to apply for the CI positions, those who were selected were given a scholarship to enroll in six hours of graduate work in the Nurse Educator tract each semester. Project planners felt that enrollment in 
nurse educator courses during the project would give the CIs theoretical knowledge in clinical instruction helpful in their
CI role. In addition, enrollment in the graduate program would support the addition of MSN-prepared nurses in the region, a much needed outcome in this community.

Table 2. Project evaluation instruments

\begin{tabular}{|c|c|c|}
\hline Evaluation Instrument & Description & Implementation Process \\
\hline $\begin{array}{l}\text { HESI examinations: } \\
\text { - } \\
\text { - } \\
\text { - } \\
\quad \text { Compedical-surgical Nursing } \\
\text { (E2) }\end{array}$ & $\begin{array}{l}\text { The HESI medical-surgical and Dosage } \\
\text { Calculation exams were 55-item content focused } \\
\text { exams. Subject matter scores on these exams } \\
\text { provide a marker of the students' progress in } \\
\text { medical-surgical nursing and prepare students for } \\
\text { the E2 and the NCLEX-RN. }{ }^{[15]} \\
\text { The HESI E2 exam is a 160-item comprehensive } \\
\text { examination, which is reflective of the } \\
\text { NCLEX-RN plan. This exam is highly predictive } \\
\text { (96.36\% to 99.16\%) of NCLEX-RN success. }{ }^{[15]}\end{array}$ & $\begin{array}{l}\text { Dosage Calculation taken during the } \\
\text { first clinical course, Basic Nursing. (All } \\
\text { cohorts) } \\
\text { Medical-surgical exam taken by } \\
\text { Cohorts } 1 \text { \& } 2 \text { in first medical-surgical } \\
\text { course. } \\
\text { Comprehensive Exit Exam taken by } \\
\text { Cohort } 1 \text { in the capstone course. }\end{array}$ \\
\hline $\begin{array}{l}\text { Basic Simulation Competence } \\
\text { Assessment }\end{array}$ & $\begin{array}{l}\text { The Basic Simulation Competency Assessment } \\
\text { involved clinical skill scenarios in which students } \\
\text { were expected to successfully respond to in order } \\
\text { to progress to the next semester. }\end{array}$ & $\begin{array}{l}\text { Taken in the first medical-surgical } \\
\text { course (all cohorts) }\end{array}$ \\
\hline Competency Transcript & $\begin{array}{l}\text { An instrument designed to assess student critical } \\
\text { thinking ability in } 10 \text { high-risk scenarios. }{ }^{[16]}\end{array}$ & $\begin{array}{l}\text { Evaluated during the capstone course } \\
\text { (Cohort 1) }\end{array}$ \\
\hline Student graduation Rates & $\begin{array}{l}\text { Graduation rates were calculated based on the } \\
\text { number of students who graduated within } 36 \\
\text { months of starting their entry-level course in the } \\
\text { nursing program. }\end{array}$ & $\begin{array}{l}\text { Calculated immediately following } \\
\text { graduation (Cohort 1) }\end{array}$ \\
\hline $\begin{array}{l}\text { Course Grades and number of } \\
\text { clinical failures }\end{array}$ & $\begin{array}{l}\text { Course grades/clinical failures for all nursing } \\
\text { students during the DEU grant period. }\end{array}$ & $\begin{array}{l}\text { Course grades/clinical failures were } \\
\text { calculated at the end of each semester. }\end{array}$ \\
\hline $\begin{array}{l}\text { Pre- and post-test scores on Student } \\
\text { Survey of Engagement (SSE) } \\
\text { instrument. }\end{array}$ & $\begin{array}{l}\text { The first SSE subscale asks about student's } \\
\text { collaborative efforts towards learning within the } \\
\text { clinical environment. The second subscale asks } \\
\text { about cognitive activities towards developing } \\
\text { knowledge and skills necessary in patient care. } \\
\text { The last subscale asks whether the experiences } \\
\text { have influenced personal development as a nurse. }\end{array}$ & $\begin{array}{l}\text { Pre-test completed soon after beginning } \\
\text { clinical experience in the first } \\
\text { medical-surgical course. } \\
\text { Post-test completed at the end of the } \\
\text { grant period. }\end{array}$ \\
\hline $\begin{array}{l}\text { Pre- and Post-test scores on Part B } \\
\text { of the QSEN Student Evaluation } \\
\text { Survey }\end{array}$ & $\begin{array}{l}\text { Part B of the QSEN Student Evaluation Survey } \\
\text { measures students’ perception of quality and } \\
\text { safety in nursing care delivery. }\end{array}$ & $\begin{array}{l}\text { Students completed the survey during } \\
\text { the first medical-surgical course and at } \\
\text { the end of the grant program. }\end{array}$ \\
\hline
\end{tabular}

\section{RESULTS}

\subsection{Objective 1: Develop and implement a DEU}

The DEU was developed and implemented as scheduled. The intent for having representatives of both organizations as a support for the project was to encourage the involvement of both the SON medical-surgical faculty and the hospital staff. However, in light of the suggested role of the SON faculty to coach the CIs in their new teaching role, these positions might have diluted the relationships of the CIs with the clinical faculty for students in the DEU. ${ }^{[4]}$

Although those participating in the orientation evaluated the experience positively, there were many staff members working on the designated units who did not participate in the orientation because of scheduling and time limitations. The orientation participants were asked to share the content of the presentations with their colleagues on their unit and the hospital nurse educator previously discussed was responsible for insuring that everyone who interacted with the students on the DEU was clear about the purpose of the project. Despite this effort, some of the DEU staff members remained unengaged in the project.

Insufficient time was allotted to the explanation of the pro- 
gram for the first cohort of students. Perhaps due to this "rushed" orientation, as previously noted, two students in the DEU group and six students in the control group refused to participate in the project. The students assigned to the DEU group who withdrew indicated that they did not intend to practice in the city in which the DEU was located following graduation. During the second semester of the project, the student orientation was lengthened to give students a greater opportunity to ask questions. This intervention increased the number of students who were willing to participate in the project. In subsequent semesters, all students assigned to the DEU agreed to participate in the project. Interestingly, students in the control group were more likely to decline to participate than those in the DEU group.

Although the willingness by students to participate in the project increased after the first semester of the project, the lack of engagement in the project by DEU staff other than the CIs became increasingly obvious as the project progressed. The hospital nurse educator made an effort, albeit informally, to encourage DEU staff to support the students. During the remainder of the project, complaints relative to the clinical experience in the DEU surfaced. Student evaluations at the end of each semester, and the results of focus groups held periodically for the CIs uncovered complaints related to a lack of understanding of the project and perhaps, disengagement of staff. Themes recurring in both student evaluations and CI focus groups included (a) lack of clarity regarding clinical objectives, (b) realistic expectations regarding student performance at various levels, (c) students feeling uncertain in their practice, and (d) students wanting to do more than "observe".

The fact that this BSN program had been using most of the hospital units as a clinical experience for years and a local Associate Degree Nursing (ADN) program also used the hospital as a clinical placement made the need for an extensive orientation even more necessary and the results of a limited orientation more problematic. The history of "the way things had been" made it difficult to introduce a new partnership with the hospital clinical nurses on the DEUs.

\subsection{Objective 2: Test the effectiveness of the DEU}

In order to evaluate the effectiveness of the DEU, the authors developed 5 hypotheses:

(1) Post-test scores on the Survey of Student Engagement (SSC) will increase over the pre-test scores for students in the DEU treatment group compared to students in the control group.

(2) There will be no difference in the scores on the HESI drug calculation, Medical-surgical and exit exams, as well as on the demonstration of identified competencies measured by the Basic Simulation Competency Published by Sciedu Press and the Competency Transcript in the DEU and control group.

(3) There will be no difference in the course grades between students in the DEU and control group.

(4) Students assigned to the DEU group will be less likely to experience clinical failures in the four medical-surgical courses than students in the control group.

(5) Post-test self-ratings regarding quality and safety competency will increase more (over the pre-test selfratings) in the DEU group as compared to the control group.

\subsection{Objective 3: Increase the number of CIs enrolled in the nurse educator program}

Two of the CIs had previously taken at least one graduate nursing course and were re-enrolled in the graduate program. One of the CIs dropped out of the graduate program at the end of the fall 2010 semester due to family issues. The remainder of the CIs continued in the graduate program in spring 2011. During the spring 2011 semester, one CI had to drop out of the MSN program due to medical complications of pregnancy; however, she continued to work as a CI on one of the DEU units. At the beginning of the fall 2011 semester, another CI decided that the graduate course work was too demanding and dropped out of the MSN program; however, she also continued to work as a CI on one of the DEU units. At the end of the spring 2012 semester, three CIs remained in the MSN-Nurse Educator Program. One CI made a career move that required transfer to another unit in the hospital (non-DEU unit), but she remained in the MSN-Nurse Educator Program. At the end of the grant period, three CIs had completed 66 semester credit hours with plans to graduate in 2014.

\section{LESSONS LEARNED \\ 4.1 Orientation}

While it is often difficult to implement a new program or process without some level of criticism from stakeholders, the program planners (Dean of the College, Chair of the $\mathrm{SON}$, and hospital CNO) felt strongly that more intensive orientation and ongoing support of the CIs and other staff on the DEU would have increased the likelihood of engagement of students and staff members in the project. A preferred time-line for planning and implementation should take at least 12 weeks. ${ }^{[17]}$ The University of Portland suggests at least a 2-semester planning and implementation phase. ${ }^{[18]}$ The timeframe for initial implementation of this project was governed by the grant parameters, since the grant was funded in August and the project began in September. However, a longer initial planning period and a stronger, more in-depth orientation, would likely have resolved some of the concerns of the participants. 
Table 3. Results of evaluation of project hypotheses

Hypothesis
Post-test scores on the Survey of Student Engagement (SSC) will
increase over the pre-test scores for students in the DEU
treatment group when compared to students in the control group.
There will be no difference in the scores on the HESI drug
calculation, Medical-surgical and exit exams, as well as on the
demonstration of identified competencies measured by the Basic
Simulation Competency and the Competency Transcript in the
DEU and control group.

There will be no difference in the course grades between students in the DEU and control group.

Students assigned to the DEU group will be less likely to experience clinical failures in the four medical-surgical courses than students in the control group.

Post-test self-ratings regarding quality and safety competency will increase more (over the pre-test self-ratings) in the DEU group as compared to the control group.

\section{Results of Evaluation*}

Hypothesis partially rejected. There were no difference in the SSE scores of the students in the DEU group and the control group with one exception. Students in the DEU group (Cohort I) perceived their own progress in personal development as a nurse were significantly higher than those in the control group. This was the only area where the DEU group scored higher than the control group.

Hypothesis accepted. No difference in any of the identified evaluation measures offered throughout the curriculum.

Hypothesis accepted. The first cohort completed all 5 identified courses, the second cohort, 4 courses; the third cohort, 3 courses; and the fourth cohort, 2 courses. The grades of the control group of the second cohort were not significantly higher than the DEU group ( $t=0.23 ; p=.04)$.

Hypothesis rejected. No students in either the DEU or control groups posted a clinical failure.

Hypothesis rejected. There was no difference in the scores in the pre-test and post-test in the DEU or control group. This was due, in part, to the high scores of both groups on the pre-test.

*The number of students involved in this project was dictated by the space available in the designated DEUs. The resulting sample size was insufficient to determine significance.

A comprehensive orientation of all who participate in a DEU project to the goals of the project is critical to the overall success of a DEU. One study revealed that staff working in a successful DEU received more professional development and support from faculty members than their counterparts in traditional units. ${ }^{[4]}$ This finding reinforces the conclusion of the project planners that the limited orientation and the informal nature of the ongoing support for the CIs and other staff certainly played a part in the lack of engagement and satisfaction of all concerned. Although this project did have a prescribed orientation for the students (1 hour) and the Clinical Instructors and the managers of the hospital staff (4 hours), none of the planned orientations proved sufficient for all of those involved in the project to feel confident in meeting the goals of the project.

Based upon our experience, we recommend that the student orientation should include (a) reasons students are assigned to a DEU and (b) the direct benefits of this assignment to them (the students) personally. As the second cohort of students in this project began their experience with the DEU, we found that the positive experiences of the previous cohort encouraged the next group to more readily accept the assignment. Had we invested more time during the first ori- entation in discussing the logistics of the project; the roles of the students, clinical preceptor, and hospital staff; the theoretical underpinnings of the project; and our expectations for success, we believe the integration, particularly of the first cohort, into the community of the unit would have been easier to accomplish.

Similarly, we should have planned a more in-depth orientation for the Clinical Instructors and management staff, as well as the staff that did not have direct responsibilities for the students' experience. Although unit staff members were invited to the orientation, they were not required to attend, and many did not participate. Because we had limited time and resources to offer the orientation, we asked the managers and clinical preceptors to explain the project to the rest of the staff. The lack of a formal orientation for the staff had negative consequences. For example, when the Clinical Instructors asked other staff to supervise the students, which happened on occasion, their lack of knowledge about the goals and objectives of the project resulted in supervisory behaviors and expectations more common in a traditional clinical placement. These different expectations have the potential to reduce the students' commitment to the DEU nursing unit. As a result of this experience, we recommend 
that sufficient resources be allocated to insure the complete orientation of all hospital personnel, from the chief nursing officer and other administrators, to every staff member who is involved in the project or who works in the DEU. We would also recommend that the support of all involve be easily available for several semesters until the hospital staff is clearly engaged in the project.

\subsection{Clinical instructors}

In an effort to make the position of the CI attractive, the 6 nurses selected received tuition for six semester credit hours of graduate courses in the nurse educator program at the participating university for each of the four long semesters of the project. However, enrollment in six semester credit hours each semester on top of a full time job and other responsibilities at home was viewed as a burden instead of a benefit. While the content of the nurse educator courses provided the CIs with knowledge, skills, and attitudes helpful in their role as clinical instructor, the resulting stress seemed to offset any benefits. The CIs, like nurses everywhere, had multiple responsibilities at home and at work, and adding a new role at work, in addition to six hours per semester of graduate education, proved to be a major stressor for these six nurses. Those who worked the 7:00 p.m. to 7:00 a.m. shift expressed the greatest amount of stress because they were required to complete some assignments, such as teaching in a classroom, during the day, when these experiences were available.

In response, the project directors reduced the number of semester credit hours of graduate work required by the CIs and at the beginning of the third semester, made enrolling in graduate courses optional. In addition, as previously noted, one of the faculty members involved in the project was also the Coordinator of the SON Nurse Educator program. She was able to revise some of the Nurse Educator assignments to be consistent with the activities required of the CIs. Providing time and flexibility in workload when functioning as a CI could have a positive outcome on the future participation of the CIs in the DEU clinical experience. ${ }^{[19]}$ However, the workload of the CIs in any future project should be carefully considered, as overload of the CIs in this project may have had a deleterious effect on program outcomes. Although increased pay was not an option in this project, the project planners believe that offering a stipend for working as a CI could have a positive effect on the outcomes. The educational principles needed for the role of the clinical instructor could be provided through an expanded orientation process.

\subsection{DEU partner hospital}

The project's partner hospital had provided clinical experiences for students from the university partner for at least

Published by Sciedu Press twenty-five years. They also served as the clinical site for an ADN program in the region, as well as for health professions programs in both schools for a number of years. In fact, over the duration of the project, a variety of students were involved in clinical activities throughout the hospital at the same time that students were in the DEU units. Although the DEU units were reserved for nursing students in the project, it was difficult for the staff to differentiate the roles and responsibilities of staff when supervising the DEU students and those in a more traditional setting. This area of potential confusion can be avoided if the DEU is in a clinical agency without a history of clinical students. However, since this is difficult to accomplish, we recommend, as previously discussed, a comprehensive orientation and ongoing support of the staff to clarify the needs of students in a DEU.

\subsection{Evaluation}

The evaluation process for this project was broad, developed to explore the impact of the project from a variety of perspectives. However, the funded project only lasted for two years and complete evaluation results only included twenty-two Cohort I participants. Therefore, the evaluation results are only suggestive at best.

Regarding the scores of the SSE, in theory the DEU should have provided greater engagement for the students working in the DEU because of the consistency in clinical instruction and setting. However, students in the DEU completed clinical experiences with a consistent CI while the control group students completed them with a consistent faculty person. This similarity in consistency may have equalized the effect on engagement. The CIs, however, were practicing bedside nurses and their role may have increased the students' sense of realism, thereby increasing their perception of receiving greater personal development into the role. However, these conclusions should be retested in other DEU projects.

\subsection{Innovation fatigue}

SON and the partnering hospital had a long history of working together to implement a number of innovative approaches to nursing education. These approaches ranged from developing summer "extern" programs to expanding the use of preceptors throughout the hospital. Four years before the implementation of the DEU unit, the SON, a local community college, and the hospital received a 1.3 million dollar grant to develop a regional simulation center, which all partners shared. These projects significantly increased the collaboration of health care stakeholders in the area and resulted in positive outcomes for students and patients. However, these innovations also resulted in changes in a variety of processes for both the faculty and the hospital staff with whom they 
worked. As a result of the continuing push toward innovation, those involved in the DEU project may have resisted additional changes in their already complex work life. When asked to "step up" for a new innovation, faculty and hospital staff may have felt as if they were too fatigued to enthusiastically embrace the changes.

\section{Conclusion}

The literature provides evidence that the DEU approach to clinical education is an excellent strategy to prepare pre-licensure nursing students for their role upon graduation. ${ }^{[2,3,8,11,12]}$ The authors of this article also recognized advantages to this model, including the ability to increase enrollment without additional faculty. The limitations of this project include a small number of participants and restricted evaluation timeframe, which make it difficult to draw con- clusions or make comparisons to other methods of clinical instruction.

Importantly, the use of the SON DEU model did not continue beyond the grant period, in part because of the findings reported and because of leadership changes at the university, the SON, and the hospital. It is interesting to note that the DEU started by Flinders University is also no longer operational (K. Edgecombe, personal communication, October 25, 2012). Despite the positive results from evaluation of the implementation of a number of DEUs across the world, this article offers these less positive outcomes for those who will implement a DEU in the future, so that the challenges we faced can be considered in their planning.

\section{CONFlicts of InTERest Disclosure}

The authors declare that there is no conflict of interest.

\section{REFERENCES}

[1] Edgecombe K, Bowman M. The ongoing search for best practice in clinical teaching and learning: A model of nursing students' evolution to proficient novice registered nurses. Nurse Education and Practice. 2009; 9: 91-101. PMid:19058758 http://dx.doi.org /10.1016/j.nepr.2008.10.006

[2] Edgecombe K, Wotten K, Gonda J, et al. Dedicated education units: A new concept for clinical teaching and learning. Contemporary Nurse: A Journal for the Australian Nursing Profession. 1999; 8(40): 166-171. http://dx.doi.org/10.5172/conu.1999.8.4.166

[3] Joynt J, Kimball B. Blowing open the bottleneck: Designing new approaches to increase nurse education capacity. Center to Champion Nursing in America. AARP and RWJF. 2008 http://championnursing.org/resources/blowing-ope n-bottleneck-designing-new-approaches-increasenur se-education-capacity

[4] Nishioka V, Coe M, Hanita M, et al. Dedicated education unit: Nurse perspectives on their clinical teaching role. Nursing Education Perspective. 2014; 35(5): 294-300. http://dx. doi.org/10.5480/1 4-1381

[5] Nishioka V, Coe M, Hanita M, et al. Dedicated education unit: Student perspectives. Nursing Education Perspectives. 2014; 35(50): 301-307. PMid:25291925 http://dx.doi.org/10.5480/14-1 380

[6] University of Portland. Assumptions about dedicated education unit academic-service partnership. 2014. Available from: http: //www . up. edu/showimage/show . aspx?file=20799

[7] Benner P, Sutphen M, Leonard V, et al. Educating nurses: A call for radical transformation. Carnegie Foundation for the Advancement of Teaching. Stanford: Jossey-Bass. 2010.

[8] Moscato SR, Miller J, Logsdon K, et al. Dedicated education unit: Innovative clinical partner educational model. Nursing Outlook. 2007: 55(1): 31-7. PMid:17289465 http://dx. doi.org/10.1016/j.o utlook.2006.11.001

[9] Wenger E. Communities of Practice: A Brief Introduction. 2006. Available from: http://www. ewenger.com/theory/communiti es_of_practice_intro.htm

[10] Kuh GD. Assessing what really matters to student learning inside the National Survey of Student Engagement. Change: The Magazine of
Higher Learning. 2001: 33(3):10-17. http://dx.doi .org/10.10 80/00091380109601795

[11] Mulready-Shick J, Kafel K, Banister G, et al. Enhancing quality and safety competency development at the unit level: An initial evaluation of student learning and clinical teaching on dedicated education units. Journal of Nursing Education. 2009; 48(12): 716-719. PMid:20000256 http://dx.doi .org/10.3928/01484834-200 91113-11

[12] Glazer G, Ives-Erickson J, Mylott L, et al. Partnering and leadership: Core requirements for developing a dedicated education unit. Journal of Nursing Administration. 2011; 41(10): 401-406. PMid:21934426 http://dx.doi.org/10.1097/NNA.0b013e31822edd79

[13] American Association of Colleges of Nursing. Special survey on vacant faculty positions for academic year 2013-2014. 2014. Available from: http://www. aacn.nche.edu/leading-initiatives/r esearch-data/vacancy14.pdf

[14] Alinwole B. Massachusetts General Hospital Dedicated Education Unit. 2012, Sep. Available from: https://vimeo.com/7941814

[15] Zweighaft E. The impact of HESI specialty exams: The ninth HESI exit exam validity study. Journal of Professional Nursing. 2013; 29(25): S10-S6. PMid:23566499 http://dx.doi.org/10.1016 /j.profnurs. 2012.06.011

[16] Roberts K, Lockhart R, Sportsman S. A competency transcript to assess and personalize new graduate competency. Journal of Nursing Administration. 2009: 39(1): 19-25. PMid:19104283 http: //dx.doi.org/10.1097/NNA.0b013e31818e9d2b

[17] Watson S, Flotman B, Fourie W, et al. A practical guide to developing a dedicated education unit. 2012. Available from: https://akoaotearoa.ac.nz/download/ng/file/group-1 658/a-practical-guide-to-developing-a-dedicated-e ducation-unit.pdf

[18] University of Portland. Sample dedicated education unit timeline for implementation. 2014. Available from: http://www up.edu/sho wimage/show . aspx? file $=20781$

[19] Mulready-Shick J, Flanagan K. Building the evidence for dedicated education unit sustainability and partnership success. Nursing Education Perspectives. 2012: 35(5): 287-293. http://dx. doi .org/10. 5480/14-1379 